\title{
Optimizing Crude Oil Sales from Strategic Petroleum Reserves in Asia
}

\section{Jennifer Irene Considine Philipp Galkin ${ }^{2}$ \\ Abdullah Aldayel ${ }^{3}$}

'Honorary Senior Research Fellow, School of Social Sciences, University of Dundee, Scotland. Email:ji.considine@dundee.ac.uk

${ }^{2}$ Visiting Researcher, King Abdullah Petroleum Studies and Research Center (KAPSARC), Saudi Arabia.

${ }^{s}$ Senior Research Analyst, King Abdullah Petroleum Studies and Research Center (KAPSARC), Saudi Arabia.

\section{Abstract}

A joint oil stockpiling facility no more than 3 days sailing from its key markets would be ideally positioned as a Strategic Petroleum Reserve for net importing nations during times of crisis and tight markets. At other times, the facility would have additional value in its capacity to provide an excellent central location for the sale of spot crude for a crude oil marketing company or major producing company. At the same time, the sale of crude oil options to Asian markets can provide a secure and reliable source of supply during times of volatility and enhance a major producing company's market share in the region. Spot crude oil and product sales from a joint oil stockpiling facility would be able reach tight markets in a few days, and in fact would be available for pick-up in variable quantities that are appropriate for specific market disruptions. As a result, the sale of spot crude oil spread options would have the potential to address sporadic and unanticipated increases in demand without adding undue downward pressure to regional oil prices. The case study develops a model to price the sale of crude oil spread options to China from a hypothetical joint oil stockpiling facility in Northeast Asia over a 15-year period from 2016 to 2030.

Keywords: Commodity markets, Energy prices, Joint oil stockpiling, Strategic petroleum reserve, Spread options, Asia. JEL Classification: G13, Q02, Q41, C10, C58, C60, F19.

Citation | Jennifer Irene Considine; Philipp Galkin; Abdullah Aldayel (2021). Optimizing Crude Oil Sales from Strategic Petroleum Reserves in Asia. Asian Bulletin of Energy Economics and Technology, 6(1): 30-42. History:

Received: 27 January 2021

Revised: 23 February 2021

Accepted: 19 March 2021

Published: 14 April 2021

Licensed: This work is licensed under a Creative Commons

Attribution 3.0 License (c) $)$

Publisher: Asian Online Journal Publishing Group
Acknowledgement: All authors contributed to the conception and design of the study.

Funding: This study received no specific financial support.

Competing Interests: The authors declare that they have no conflict of interests.

Transparency: The authors confirm that the manuscript is an honest, accurate, and transparent account of the study was reported; that no vital features of the study have been omitted; and that any discrepancies from the study as planned have been explained.

Ethical: This study follows all ethical practices during writing.

\section{Contents}

1. Introduction 31

2. Material and Methods

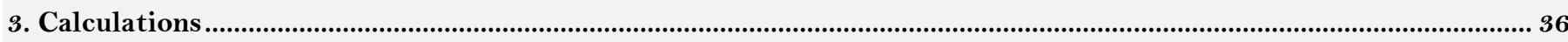

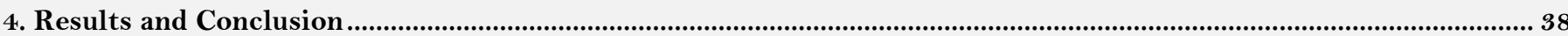

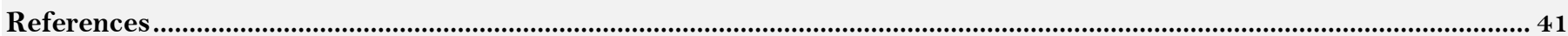




\section{Contribution of this paper to the literature}

This study contributes to existing literature by illustrating a commercially attractive way to enhance the value of Strategic Petroleum Reserves and joint oil stockpiling reserves in Northeast Asia during times of transition and volatility on global oil markets.

\section{Introduction}

In this paper, joint oil stockpiling (JOS) refers to a commercial arrangement whereby crude oil, owned and commercially traded by an exporting country, is stored in an importing country in exchange for priority drawdown by the host country in the event of an emergency. It can thus be classified as both commercial and strategic storage (Doshi \& Sammy, 2017).

The use of joint stockpiling agreements for commercial purposes, and projects involving the leasing of parts of national strategic storage facilities have been gaining popularity with major crude oil producing and trading companies since 2006 (Kilduff, 2015). These, in turn, have been used to create regional hubs or distribution centers in the race to capture market share in oil-consuming markets located a long distance from major suppliers as outlined in "Joint Oil Stockpiling between Middle East Exporters and Northeast Asian importers," (Doshi \& Sammy, 2017).To cite some examples: On Jan. 25, 2017, India signed a deal with the Abu Dhabi National Oil Company (ADNOC) to store the latter's crude in a 5.86 MMbbl underground oil storage facility in Mangalore part of India's SPR. According to Sultan Ahmed Al Jabar, United Arab Emirates (UAE) Minister of State and ADNOC CEO, "We will utilize the Mangalore Facility to not only build on our existing business relationships across India but also to explore new downstream opportunities for ADNOC's expanding range of refined and petrochemical products." Verma (2017) ADNOC has a similar agreement to store up to 6.29 million barrels (1 million kiloliters) at the Kiire oil terminal in southern Japan at no cost (Reuters, 2017). Finally, Iraqi state-oil marketer SOMO is contemplating the construction of storage facilities in South Korea in an attempt to increase sales to Asia (Rasheed, 2018).

The SPR requirements have also contributed to proliferation of such agreements. Under the terms of an agreement reached in March 2001, all members of the IEA are committed to maintaining a crude oil reserve equal to 90 days of net oil imports. The terms of the SPR vary across nations, and the situation is slightly different in Japan and South Korea. In Japan, the SPR is composed of three different types of stockpiles, state-controlled reserves, private reserves of petroleum held in accordance with the Petroleum Stockpiling Law and private reserves of petroleum products. In South Korea, refiners, specific distributors, and importers are obligated to hold $40-60$ days of their daily imports, and sales of refined products based on a lagged 12-month average.

Sales of spread options from regional joint stockpiling facilities have the potential to enhance MOC's market share of local and nearby markets. The case study develops a model to price the sale of crude oil spread options to China from a hypothetical joint oil stockpiling facility in Northeast Asia over a 15-year period from 2016 to 2030.

One of the examples of a JOC in Northeast Asia is the Okinawa facility. It is one of six private bases selected by Japan's Ministry of Economy, Trade, and Industry (METI) to facilitate the strategic drawdown of national reserves. In an early stage or pre-emergency, approximately $20 \mathrm{MMbbl}$ of oil will be drawn down from several national and private sector bases.

The METI order clearly defines the use of a market mechanism to distribute the oil, which will be executed by competitive bidding to successful competitors. The sales bidding is expected to be completed within 13 days of the METI Ministerial Order requesting the drawdown of national reserves in case of an emergency (JNOC, 20O1). Contracts are awarded to successful bidders over the next seven days of the process. The response schedule is as follows:

- Day 1: METI decides to draw down national reserves.

- Day 1-13: A Notice of Sale is issued

- Day 14-20: Contracts are awarded to successful bidders.

- Day 21-28: The facility prepares to start drawdown.

- Day 21: Crude oil is delivered by tanker to the successful bidder(s) (JNOC, 2001).

This paper is organized as follows.

The second section, "Materials and Methods" outlines the assumptions underlying the sale of spread options and formulates the problem in terms of a simple European spread option.

The third section shows estimation of the relationship between benchmark Dubai Crude and the three main Saudi Arabian export crude grades, the relationship between Brent and Saudi Arabian crudes, and potential incremental value of spot sales from the hypothetical JOS facility. The main underlying assumption of these sections is that the spot sales of crude oil have no impact on world oil prices and that the sale of oil under shortterm and long-term contracts to existing customers is unaffected.

The results are reported in the "Results and Conclusion" section, which outlines some possible areas for further research.

Finally, the project model is laid out in detail in the Appendix.

\section{Material and Methods}

\subsection{Project Assumptions}

The reference or base case value of crude oil options from the leased facilities of a hypothetical JOS facility is calculated from the perspective of a MOC located a long distance away from potentially lucrative market centers. For the purpose of this analysis, the MPT for a major supplier is located more than 25 days' sailing from key markets in Northeast Asia, such as the Chinese port of Qingdao which services a number of China's teapot refiners (Phua \& Jean, 2016).

The four assumptions underlying the valuation model can be listed as follows: 1: The major producing company, MOC, can store approximately 6.2 MMbbl of crude oil free of charge throughout the project lifetime. 
2: In return for the free use of storage facilities, the owner of the JOS gets a priority claim on the oil stocks in case of an emergency.

3: The storage facility owner can claim the crude oil storage at the JOS as quasi-government inventory so that

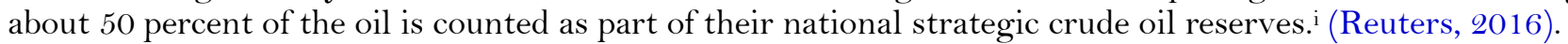

4: The value of utilizing a JOS storage facility for commercial purposes derives primarily from its proximity to key markets in Asia (three-days' sailing at average speeds permits the sale of spot crude from the JOS to buyers in the region). From the NOC perspective, this adds considerable value as the voyage from a major oil export port to, for example, Qingdao, China, takes well over 25 days - too long for profitable spot sales to the area.

\subsection{Hypothetical Terms of Operation}

Under the terms of our hypothetical agreement, the volumes of crude oil supplies are held in storage by the MOC and can be used to supply Asian customers on a term basis, for term sales or long-term deals signed months in advance. Their use for spot sales during times of high oil prices is relatively new and adds considerable value to any such joint storage agreement.

Concerning the effects of an increased supply of crude on the crude oil price, the study assumes liquid forward and futures markets, so that all these operations can be completed and hedged at the market prices at the time of execution. Finally, a number of factors leading to tight markets, and supply and demand shocks can contribute to a sudden and short-term increase in spot prices in Asia. For example, independent refiners in China are often caught short at the end of the year as they struggle to meet the provincial government's crude oil import targets (Platts, 2016).

\subsection{Data Inputs}

In our hypothetical case study, a regionally sited JOS (on the island of Okinawa, Japan) provides storage facilities for 6.2 MMbbl crude and refined oil products. Assuming 50 percent of these volumes are reserved for strategic stockpiles, with 0.99 percent slippage, about $3 \mathrm{MMbbl}$ can be used for spot sales to Asian markets (any potential slippage is due to leaks and errors in the physical drawdown procedure). This value is a conservative minimum approximation. Any major oil producing, or marketing company will have the capacity to send VLCCs carrying up to as much as 2.1 MMbbl each and even ULCCs carrying up to $3 \mathrm{MMbbl}$ each, rotating between a major port in close proximity to the supply source and a JOS.

Assuming crude oil production costs of $\$ 3 / \mathrm{bbl}$, transportation costs from MPT to JOS of $\$ 1.65 / \mathrm{bbl}$ and a sale of 100 percent Arabian Medium crude, the gross income from these sales, at current oil prices, is approximately $\$ 98$ million per annum, yielding a NPV of $\$ 1.45$ billion at a 2.5 percent discount rate (see Table 1 ).

Arabian Medium is - as the name suggests - the main medium gravity grade crude exported by Saudi Arabia. For physical spot sales it, and most other regional crudes, is priced at a differential to the regional crude benchmark, Dubai, as assessed by the United States (U.S.)-based price reporting agency Platts, a division of S\&P Global (Platts, 2018).

Table 1 lists the assumptions underlying these projections for sales of Arabian Medium export crude on a FOB basis at MPT, no taxes, or operating expenses for the facility, free lease of crude oil storage, 50 percent strategic oil requirements and spot sales of $3 \mathrm{MMbbl}$ per year from a regional JOS facility.

We used the futures curve for benchmark Dubai crude to estimate the futures curves for the three main grades of Saudi Arabian export crudes (CME Group, 2016). Specifically, the relationship between Arabian Medium and Dubai Moo 1 was estimated by simple two variable regression analyses. The results of these analyses are presented in Table 2 .

Note: Dubai is the regional crude benchmark, Arabian Light, Medium and Heavy are Saudi Arabia's three main export grades. Moo1 refers to the current month until two days (not business days) before the end of the month (Platts, 2018).

We construct a base case scenario in which we assume 50 percent of the storage facility's crude oil capacity is available for sale on the spot market once per annum. We also assume that there is a 21-28-day period required between a ministerial order for strategic drawdown and delivery, and a 24-day vessel journey from MPT to Qingdao port and other similar markets in Northeast Asia. Under these assumptions, there is ample opportunity to make more than one trip per year. Many such trips could be made per year without disrupting the crude oil supplies available for strategic purposes.

The assumption that the reference level of crude oil sales of $3 \mathrm{MMbbl}$ per year is a very conservative estimate. Clearly, given the capacity to make numerous deliveries of crude oil to JOS per year to replenish the required volume of strategic oil inventories, the facility holds substantially more capacity for short-term sales than the base value presented in Table 1.

\subsection{The Value of a Spread Option on Spot Crude Oil Sales from Joint Stockpiles}

Spread options derive their value from the difference in prices between two or more assets. They are generally traded over the counter rather than on an exchange. In commodity markets spread options are often based on the difference in asset prices between two or more locations, points on the calendar, grades or quality of the energy source and inputs vs. outputs in the production process, such as spark spreads and crack spreads (Carmona \& Durrleman, 2003). This example is based on location spread or the difference between crude oil prices in two different locations.

The fair value of the spread call option reflects the fair market value of the right, but not the corresponding obligation, to purchase spot crude from the MOC, FOB at JOS, for final delivery in Asian markets (e.g., Qingdao) at a given exercise price at a future date. The exercise, or strike, price is the cost of transporting the crude oil between JOS and Qingdao at some future date, t. 


\begin{tabular}{|c|c|c|c|c|c|c|c|c|c|c|c|c|c|c|c|}
\hline 2016 & & 2017 & 2018 & 2019 & 2020 & 2021 & 2022 & 2023 & 2024 & 2025 & 2026 & 2027 & 2028 & 2029 & 2030 \\
\hline \multicolumn{16}{|c|}{ Physical Quantities Million Barrels } \\
\hline Storage Capacity & 6.20 & 6.20 & 6.20 & 6.20 & 6.20 & 6.20 & 6.20 & 6.20 & 6.20 & 6.20 & 6.20 & 6.20 & 6.20 & 6.20 & 6.20 \\
\hline Required Strategic Oil & 3.10 & 3.10 & 3.10 & 3.10 & 3.10 & 3.10 & 3.10 & 3.10 & 3.10 & 3.10 & 3.10 & 3.10 & 3.10 & 3.10 & 3.10 \\
\hline Slippage & $99 \%$ & & & & & & & & & & & & & & \\
\hline $\begin{array}{l}\text { Percent of Strategic Oil } \\
\text { Required }\end{array}$ & $50 \%$ & & & & & & & & & & & & & & \\
\hline \multicolumn{16}{|c|}{ Physical Quantities Million Barrels } \\
\hline Storage Capacity & 6.13 & 6.13 & 6.13 & 6.13 & 6.13 & 6.13 & 6.13 & 6.13 & 6.13 & 6.13 & 6.13 & 6.13 & 6.13 & 6.13 & 6.13 \\
\hline Required Strategic Oil & 3.07 & 3.07 & 3.07 & 3.07 & 3.07 & 3.07 & 3.07 & 3.07 & 3.07 & 3.07 & 3.07 & 3.07 & 3.07 & 3.07 & 3.07 \\
\hline \multicolumn{16}{|l|}{ Contract Revenue } \\
\hline 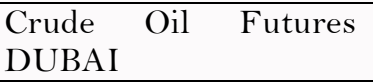 & $\$ 48.66$ & $\$ 46.96$ & $\$ 50.22$ & $\$ 52.43$ & $\$ 53.59$ & $\$ 41.31$ & $\$ 41.31$ & $\$ 41.31$ & $\$ 41.31$ & $\$ 41.31$ & $\$ 41.31$ & $\$ 41.31$ & $\$ 41.31$ & $\$ 41.31$ & $\$ 41.31$ \\
\hline Arab Light Futures & $\$ 48.21$ & $\$ 46.43$ & $\$ 49.84$ & $\$ 52.14$ & $\$ 53.36$ & $\$ 40.53$ & $\$ 40.53$ & $\$ 40.53$ & $\$ 40.53$ & $\$ 40.53$ & $\$ 40.53$ & $\$ 40.53$ & $\$ 40.53$ & $\$ 40.53$ & $\$ 40.53$ \\
\hline Volume of Arab Light & $0 \%$ & - & - & - & - & - & - & - & - & - & - & - & - & - & - \\
\hline \multicolumn{16}{|c|}{ Assumed \% of Arab Light } \\
\hline Arab Medium Futures & $\$ 46.90$ & $\$ 45.14$ & $\$ 48.53$ & $\$ 50.82$ & $\$ 52.03$ & $\$ 39.27$ & $\$ 39.27$ & $\$ 39.27$ & $\$ 39.27$ & $\$ 39.27$ & $\$ 39.27$ & $\$ 39.27$ & $\$ 39.27$ & $\$ 39.27$ & $\$ 39.27$ \\
\hline 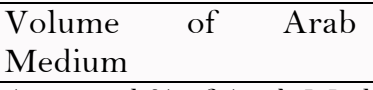 & \begin{tabular}{|r|}
$100 \% \quad \$$ \\
3.07 \\
\end{tabular} & $\$ 3.07$ & $\$ 3.07$ & $\$ 3.07$ & $\$ 3.07$ & $\$ 3.07$ & $\$ 3.07$ & $\$ 3.07$ & $\$ 3.07$ & $\$ 3.07$ & $\$ 3.07$ & $\$ 3.07$ & $\$ 3.07$ & $\$ 3.07$ & $\$ 3.07$ \\
\hline \multicolumn{16}{|c|}{ Assumed \% of Arab Medium } \\
\hline Arab Heavy Futures & $\$ 45.22$ & $\$ 43.48$ & $\$ 46.82$ & $\$ 49.08$ & $\$ 50.27$ & $\$ 37.69$ & $\$ 37.69$ & $\$ 37.69$ & $\$ 37.69$ & $\$ 37.69$ & $\$ 37.69$ & $\$ 37.69$ & $\$ 37.69$ & $\$ 37.69$ & $\$ 37.69$ \\
\hline Volume of Arab Heavy & $0 \%$ & - & - & - & - & - & - & - & - & - & - & - & - & - & - \\
\hline \multicolumn{16}{|c|}{ Assumed \% of Arab Heavy } \\
\hline \multicolumn{16}{|l|}{ Total Revenue } \\
\hline $\begin{array}{l}\text { Spot Sales Revenue AL } \\
\$ \text { Million }\end{array}$ & - & $\$-$ & $\$-$ & $\$-$ & $\$-$ & $\$-$ & $\$-$ & $\$-$ & $\$-$ & $\$-$ & $\$-$ & $\$-$ & $\$-$ & $\$-$ & $\$-$ \\
\hline $\begin{array}{lcl}\text { Spot Sales } & \text { Revenue } \\
\text { AM } \$ \text { Million } & \\
\end{array}$ & $\$ 143.88$ & $\$ 138.47$ & $\$ 148.85$ & $\$ 155.89$ & $\$ 159.60$ & $\$ 120.46$ & $\$ 120.46$ & $\$ 120.46$ & $\$ 120.46$ & $\$ 120.46$ & $\$ 120.46$ & $\$ 120.46$ & $\$ 120.46$ & $\$ 120.46$ & $\$ 120.46$ \\
\hline $\begin{array}{l}\text { Spot Sales Revenue AL } \\
\$ \text { Million }\end{array}$ & - & $\$-$ & $\$-$ & $\$-$ & $\$-$ & $\$-$ & $\$-$ & $\$-$ & $\$-$ & $\$-$ & $\$-$ & $\$-$ & $\$-$ & $\$-$ & $\$-$ \\
\hline Total Revenue & $\$ 143.88$ & $\$ 138.47$ & $\$ 148.85$ & $\$ 155.89$ & $\$ 159.60$ & $\$ 120.46$ & $\$ 120.46$ & $\$ 120.46$ & $\$ 120.46$ & $\$ 120.46$ & $\$ 120.46$ & $\$ 120.46$ & $\$ 120.46$ & $\$ 120.46$ & $\$ 120.46$ \\
\hline Inflation & $2.5 \%$ & & & & & & & & & & & & & & \\
\hline \multicolumn{16}{|c|}{ Costs of Crude Oil Supplies } \\
\hline \multicolumn{16}{|l|}{ Crude Oil Supplies } \\
\hline \multicolumn{16}{|c|}{ Production Costs per Barrel } \\
\hline $\begin{array}{lll}\begin{array}{l}\text { Production Costs } \\
\text { Barrel }\end{array} & & \\
\end{array}$ & $\begin{array}{|rr|}3.00 \quad \$ \\
9.20 \\
\end{array}$ & $\$ 9.43$ & $\$ 9.67$ & $\$ 9.91$ & $\$ 10.16$ & $\$ 10.41$ & $\$ 10.67$ & $\$ 10.94$ & $\$ 11.21$ & $\$ 11.49$ & $\$ 11.78$ & $\$ 12.07$ & $\$ 12.38$ & $\$ 12.69$ & $\$ 13.00$ \\
\hline $\begin{array}{l}\text { Transportation Cost } \\
\text { from Ras Tanura to } \\
\text { Okinawa }\end{array}$ & \begin{tabular}{|lr}
1.65 & $\$$ \\
& 5.06
\end{tabular} & $\$ 5.19$ & $\$ 5.32$ & $\$ 5.45$ & $\$ 5.59$ & $\$ 5.73$ & $\$ 5.87$ & $\$ 6.02$ & $\$ 6.17$ & $\$ 6.32$ & $\$ 6.48$ & $\$ 6.64$ & $\$ 6.81$ & $\$ 6.98$ & $\$ 7.15$ \\
\hline \multicolumn{16}{|l|}{ Operating Expenses } \\
\hline Operating & $\begin{array}{|rr|}0.50 & \$ \\
0.50\end{array}$ & $\$ 0.51$ & $\$ 0.53$ & $\$ 0.54$ & $\$ 0.55$ & $\$ 0.57$ & $\$ 0.58$ & $\$ 0.59$ & $\$ 0.61$ & $\$ 0.62$ & $\$ 0.64$ & $\$ 0.66$ & $\$ 0.67$ & $\$ 0.69$ & $\begin{array}{lll} & 0.71\end{array}$ \\
\hline
\end{tabular}


Asian Bulletin of Energy Economics and Technology, 2021, 6(1): 30-42

\begin{tabular}{|c|c|c|c|c|c|c|c|c|c|c|c|c|c|c|c|}
\hline Other & $\begin{array}{|rr|}0.50 \quad \$ \\
0.50 \\
\end{array}$ & $\$ 0.51$ & $\$ 0.53$ & $\$ 0.54$ & $\$ 0.55$ & $\$ 0.57$ & $\$ 0.58$ & $\$ 0.59$ & $\$ 0.61$ & $\$ 0.62$ & $\$ 0.64$ & $\$ 0.66$ & $\$ 0.67$ & $\$ 0.69$ & $\$ 0.71$ \\
\hline $\begin{array}{ll}\text { Total } & \text { Operating } \\
\text { Expenses } & \end{array}$ & $\$ 15.26$ & $\$ 15.65$ & $\$ 16.04$ & $\$ 16.44$ & $\$ 16.85$ & $\$ 17.27$ & $\$ 17.70$ & $\$ 18.14$ & $\$ 18.60$ & $\$ 19.06$ & $\$ 19.54$ & $\$ 20.03$ & $\$ 20.53$ & $\$ 21.04$ & $\$ 21.57$ \\
\hline & - & $\$-$ & $\$-$ & $\$-$ & $\$-$ & $\$-$ & $\$-$ & $\$-$ & $\$-$ & $\$-$ & $\$-$ & $\$-$ & $\$-$ & $\$-$ & $\$-$ \\
\hline $\begin{array}{ll}\text { Gross Income Without } \\
\text { Option } & \text { Value: } \\
\text { EBITDA } & \end{array}$ & $\$ 128.61$ & $\$ 122.82$ & $\$ 132.81$ & $\$ 139.45$ & $\$ 142.75$ & $\$ 103.19$ & $\$ 102.76$ & $\$ 102.32$ & $\$ 101.86$ & $\$ 101.40$ & $\$ 100.92$ & $\$ 100.43$ & $\$ 999.93$ & $\$ 99.42$ & $\$ 998.89$ \\
\hline NPV & \begin{tabular}{|l|}
$\$ 126.09$ \\
\end{tabular} & $\$ 244.14$ & $\$ 369.30$ & $\$ 498.13$ & $\$ 627.42$ & $\$ 719.05$ & \begin{tabular}{|l|l}
$\$ 808.51$ \\
\end{tabular} & $\$ 895.84$ & $\$ 981.07$ & $\begin{array}{l}\$ \\
1,064.26\end{array}$ & $\begin{array}{l}\$ \\
1,145.42\end{array}$ & $\begin{array}{l}\$ \\
1,224.61\end{array}$ & \begin{tabular}{|l|}
$\$$ \\
$1,301.87$
\end{tabular} & \begin{tabular}{|l|}
$\$$ \\
$1,377.21$ \\
\end{tabular} & $\begin{array}{l} \\
1,450.69\end{array}$ \\
\hline
\end{tabular}


In short, the potential incremental value of sales of spot crude spread options, in this case Arabian Medium, from JOS, can be valued as the fair value of a spread call option between two points:

1. Crude deliveries FOB JOS at time $t$

2. Crude deliveries FOB to Qingdao port, China at time $t$

Note: The distance from the study's JOS in Naha Okinawa, Japan to Qingdao, China is approximately 736 nautical miles and takes just over three days to complete at an average speed of 10 knots (Sea- distances.org and the KAPSARC Global Trade Oil Model).

The Appendix specifies the mathematical model for a spread option and provides more detail. However, in summary, the project assumptions specifying the terms of the option are:

1. Type of exercise right: European

2. Exercise price level: the cost of freight to transport the crude oil from JOS to Qingdao.

3. Expiration date: two months

The call spread option is in the black if the cost of transporting a competing crude to Qingdao minus the price of Arabian Medium FOB JOS is greater than the cost of transporting the crude from JOS to Qingdao. The option is out of the money when the cost of getting a competing crude to Qingdao minus the price of Arabian Medium FOB JOS is less than or equal to the cost of transporting the crude from JOS to Qingdao.

\begin{tabular}{|c|c|c|c|c|c|c|}
\hline \multicolumn{7}{|l|}{ Regression equation } \\
\hline \multicolumn{7}{|l|}{$\begin{array}{l}\text { Arab Light }=-2.62482437+ \\
1.04466961 \text { Dubai Mo01 }\end{array}$} \\
\hline $\begin{array}{l}\text { Multiple regression for Arab } \\
\text { Light }\end{array}$ & \multirow{2}{*}{$\begin{array}{l}\text { Multiple } \\
\quad \mathbf{R}\end{array}$} & \multirow{2}{*}{ R-square } & \multirow{2}{*}{$\begin{array}{l}\text { Adjusted } \\
\text { R-square }\end{array}$} & \multirow{2}{*}{$\begin{array}{l}\text { Std. err. } \\
\text { of } \\
\text { estimate }\end{array}$} & & \\
\hline \multirow[t]{3}{*}{ Summary } & & & & & & \\
\hline & 0.9988 & 0.9977 & 0.9977 & 1.469645 & & \\
\hline & \multirow{2}{*}{$\begin{array}{l}\text { Degrees of } \\
\text { freedom }\end{array}$} & \multirow{2}{*}{$\begin{array}{l}\text { Sum of } \\
\text { squares }\end{array}$} & \multirow{2}{*}{$\begin{array}{l}\text { Mean of } \\
\text { squares }\end{array}$} & \multirow{2}{*}{$\mathbf{F}$} & \multirow{2}{*}{ p-value } & \\
\hline ANOVA table & & & & & & \\
\hline Explained & 1 & 779305.7 & 779305.7 & 360813.7 & $<0.0001$ & \\
\hline \multirow[t]{2}{*}{ Unexplained } & 838 & 1809.959 & 2.159856 & & & \\
\hline & \multirow[t]{2}{*}{ Coefficient } & \multirow{2}{*}{$\begin{array}{l}\text { Standard } \\
\text { error }\end{array}$} & \multirow[t]{2}{*}{ t-value } & \multirow[t]{2}{*}{ p-value } & \multicolumn{2}{|c|}{$\begin{array}{c}\text { Confidence interval } \\
95 \% \\
\end{array}$} \\
\hline Regression table & & & & & Lower & Upper \\
\hline Constant & -2.62482 & 0.139083 & -18.8723 & $<0.0001$ & -2.89782 & -2.35183 \\
\hline Dubai Mo01 & 1.04467 & 0.001739 & 600.6777 & $<0.0001$ & 1.041256 & 1.048083 \\
\hline \multicolumn{7}{|l|}{ Regression Equation } \\
\hline \multicolumn{7}{|c|}{$\begin{array}{l}\text { Arab Medium + (Dubai+Oman }) / 2=- \\
3.63390492+1.03867596 \text { Dubai Moo1 }\end{array}$} \\
\hline $\begin{array}{l}\text { Multiple regression for Arab } \\
\text { Medium }+(\text { Dubai }+ \text { Oman }) / 2\end{array}$ & \multirow{2}{*}{$\begin{array}{l}\text { Multiple } \\
\mathbf{R}\end{array}$} & \multirow[t]{2}{*}{ R-square } & \multirow{2}{*}{$\begin{array}{l}\text { Adjusted } \\
\text { R-square }\end{array}$} & \multirow{2}{*}{$\begin{array}{c}\text { Std. err. } \\
\text { of } \\
\text { estimate }\end{array}$} & & \\
\hline \multirow[t]{3}{*}{ Summary } & & & & & & \\
\hline & 0.9984 & 0.9968 & 0.9968 & 1.724515 & & \\
\hline & \multirow{2}{*}{$\begin{array}{l}\text { Degrees of } \\
\text { freedom }\end{array}$} & Sum of & Mean of & $\mathbf{F}$ & p-value & \\
\hline ANOVA table & & & squares & & & \\
\hline Explained & 1 & 766770.2 & 766770.2 & 257828.6 & $<0.0001$ & \\
\hline Unexplained & 835 & 2483.251 & 2.973953 & & & \\
\hline & Coefficient & Standard & t-value & p-value & $\begin{array}{r}\text { Confiden } \\
9 \\
\end{array}$ & $\begin{array}{l}\text { interval } \\
\text { o }\end{array}$ \\
\hline Regression table & & & & & Lower & Upper \\
\hline Constant & -3.6339 & 0.163348 & -22.2464 & $<0.0001$ & -3.95453 & -3.31328 \\
\hline Dubai Mo01 & 1.038676 & 0.002046 & 507.7683 & $<0.0001$ & 1.034661 & 1.042691 \\
\hline Regression equation & & & & & & \\
\hline $\begin{array}{l}\text { Arab Heavy + (Dubai+Oman) } \\
4.58852152+1.0236342 \text { Dub }\end{array}$ & & & & & & \\
\hline $\begin{array}{l}\text { Multiple regression for Arab } \\
\text { Heavy }+(\text { Dubai+Oman }) / 2\end{array}$ & $\underset{\mathbf{R}}{\text { Multiple }}$ & R-square & Adjusted & $\begin{array}{l}\text { Std. err. } \\
\text { of }\end{array}$ & & \\
\hline Summary & & & & estimate & & \\
\hline & 0.9982 & 0.9964 & 0.9964 & 1.804712 & & \\
\hline & Degrees of & Sum of & Mean of & $\mathbf{F}$ & n-value & \\
\hline ANOVA Table & freedom & squares & squares & $\mathbf{F}$ & p-vaiue & \\
\hline Explained & 1 & 744722.8 & 744722.8 & 228654.1 & $<0.0001$ & \\
\hline Unexplained & 835 & 2719.582 & 3.256984 & & & \\
\hline & Coefficient & Standard & t-value & p-value & $\begin{array}{r}\text { Confiden } \\
9 \\
\end{array}$ & interval \\
\hline Regression Table & & & & & Lower & Upper \\
\hline Constant & -4.58852 & 0.170944 & -26.8422 & $<0.0001$ & -4.92405 & -4.25299 \\
\hline Dubai Mo01 & 1.023634 & 0.002141 & 478.1779 & $<0.0001$ & 1.019432 & 1.027836 \\
\hline
\end{tabular}


Once estimated the option's fair market value will give an excellent approximation of the value of the transportation between JOS and Qingdao. Or equivalently, the option's value reflects the amount of money a market player would pay to a MOC today - over and above the transportation costs - to reserve the right to buy spot crude for delivery at a future date.

Unsurprisingly, given the volatility of crude oil prices, the level of competition for market share in Asia can be significant and includes a number of shipments from distances exceeding 20 sailing days. To cite one example, China imported crude oil from the U.S. and Canada, including 213,705 bbl transported from the San Francisco area in April 2015 (Bloomberg Staff, 2015). Since that time, Chinese imports from the U.S. have continued to increase, exceeding $8 \mathrm{MMbbl}$ of U.S. light crude in February 2017 (Traywick \& Sheela, 2017).

The price p, or the fair market value of the European spread option is given by the following equation detailed in Equations 1-7 in the Appendix:

$$
p=e^{-r T} \iint\left(s_{2}-s_{1}-K\right)^{+} f_{T}\left(s_{1} s_{2}\right) d_{s_{1}} d_{s_{2}}
$$

Where:

1. $\mathrm{K}=$ The exercise price level: The cost of freight to transport crude from JOS to Qingdao.

2. $\mathrm{T}=$ The expiration date: The option is expected to expire two months after the value or settlement date.

3. $\mathrm{S}_{1}(\mathrm{O})=$ The price of crude FOB at Qingdao port.

4. $\mathrm{S}_{2}(\mathrm{O})=$ The price of MOC crude of comparable API FOB JOS at time t. (The American Petroleum Industry gravity (API gravity) is the standard measure of how light or heavy a petroleum liquid is when compared to water.)

5. $r=$ The short-term risk-free interest rate.

Note: The spot price of Arabian Heavy, Medium and Light (as assessed by Platts) plus the cost of sea transportation from MPT to JOS of approximately $\$ 1.65 / \mathrm{bbl}$ was estimated using Sea-distances.org, and the KAPSARC Global Trade Oil Model with the total cost estimated using the KAPSARC Global Trade Oil Model (Al-Kathiri, Yazeed, Tilak, \& Frederic, 2017)

\section{Calculations}

\subsection{Estimating the Relationship between Benchmark Dubai Crude and the Three Main Saudi Arabian Export} Crude Grades

The futures curve for Dubai crude was used to estimate the futures curves for Arabian crudes (CME Group, 2016; Platts, 2016). Specifically, the relationship between Arabian Light, Medium and Heavy crudes, and Dubai MoO1 was estimated by simple two variable regression analyses. Table 2 presents the results of these analyses.

\subsection{Estimating the Relationship between Brent and Saudi Arabian Crudes}

We used the futures curve for benchmark Brent crude to estimate the futures curves for the minimum price of crude delivered FOB at Qingdao (CME Group, 2016). Specifically, the relationship between Brent and the minimum price of Saudi Arabian export grades of Light, Medium, and Heavy crudes was estimated by a simple twovariable regression analysis. The results are presented in Table 3 (Platts, 2016).

\subsection{Potential Incremental Value of Spot Sales from the Hypothetical JOS Facility}

Given the following assumptions:

1. Type of exercise right: European

2. Exercise price level: Cost of freight to transport the crude oil from JOS to Qingdao is $\$ 0.82 / \mathrm{bbl}$.

3. Expiration date $\mathrm{T}$ : The option is expected to expire two months after the value or settlement date.

4. $\mathrm{S}_{1}(0)=$ The compound price index computed from the aggregation of several other financial instruments reflecting the minimum price at time $t$ of all competing crudes FOB to China's Qingdao port.

a. The minimum light grade is the Platts daily price of ESPO MoO1 FOB Qingdao port at time 0.

b. The minimum medium grade is the minimum of the Platts daily price of Dubai Moo1 and Castilla Blend FOB Qingdao port at time 0 .

c. The minimum heavy grade is the minimum of the Platts daily price of Cold Lake Blend Hardisty Canada, Kern River, and WCS Hardisty Canada FOB Qingdao port at time O.

5. $\mathrm{S}_{2}(0)=$ The price of MOC crude of comparable API FOB JOS at time $t$.

a. The price of Arabian Light FOB JOS at time t-O.

b. The price of Arabian Medium FOB JOS at time $t=0$.

c. The price of Arabian Heavy FOB JOS at time $\mathrm{t}=0$.

6. $\mathrm{r}=2.5$ percent

7. The forward curves for Brent and Dubai at time $t=0$.

8. Six sales of options per year.

9. The correlation coefficients between the various crude prices.

Table 4 lists the fair market annual options values for incremental spot oil sales from the JOS facility.

The options value of the JOS facility is equal to the NPV of the reference case, plus the options value calculated in Table 4. Assuming crude oil production costs of $\$ 3 / \mathrm{bbl}$, transportation costs from MPT to JOS of $\$ 1.65 / \mathrm{bbl}$ and assumed spot sales FOB JOS of 33 percent of the available capacity of Arabian Medium, 33 percent of Arabian Heavy and 33 percent of Arabian Light crude, the gross revenue from these sales is approximately $\$ 94$ million per annum. This yields an NPV of $\$ 1.61$ billion at a 2.5 percent discount rate (see Table 5). 
Table-3. Regression results (Brent / Saudi crudes)

\begin{tabular}{|c|c|c|c|c|c|c|}
\hline Regression equation & & & & & & \\
\hline \multicolumn{7}{|c|}{ Min Cold Lake WCS Kern@Qingdao=3.3559321 + 0.82043253 Brent M1 } \\
\hline $\begin{array}{l}\text { Multiple Regression for Min Cold } \\
\text { LakeWCSKern@Qingdao }\end{array}$ & \multirow{2}{*}{$\begin{array}{l}\text { Multiple } \\
\quad \text { R }\end{array}$} & \multirow[t]{2}{*}{ R-square } & \multirow{2}{*}{$\begin{array}{c}\text { Adjusted } \\
\text { R- } \\
\text { square }\end{array}$} & \multirow{2}{*}{$\begin{array}{l}\text { Std. err. } \\
\text { of } \\
\text { estimate }\end{array}$} & & \\
\hline Summary & & & & & & \\
\hline & 0.9509 & 0.9043 & 0.9042 & 7.226804 & & \\
\hline & \multirow{2}{*}{$\begin{array}{l}\text { Degrees of } \\
\text { freedom }\end{array}$} & \multirow{2}{*}{$\begin{array}{l}\text { Sum of } \\
\text { squares }\end{array}$} & \multirow{2}{*}{$\begin{array}{l}\text { Mean of } \\
\text { squares }\end{array}$} & \multirow{2}{*}{$\mathbf{F}$} & \multirow{2}{*}{ p-value } & \\
\hline ANOVA table & & & & & & \\
\hline Explained & 1 & 1062344 & 1062344 & 20341.01 & $<0.0001$ & \\
\hline \multirow[t]{2}{*}{ Unexplained } & 2153 & 112444.1 & 52.2267 & & & \\
\hline & \multirow[t]{2}{*}{ Coefficient } & \multirow{2}{*}{$\begin{array}{l}\text { Standard } \\
\text { error }\end{array}$} & \multirow[t]{2}{*}{ t-value } & \multirow[t]{2}{*}{ p-value } & \multicolumn{2}{|c|}{$\begin{array}{c}\text { Confidence interval } \\
95 \% \\
\end{array}$} \\
\hline Regression table & & & & & Lower & Upper \\
\hline Constant & 3.355932 & 0.526633 & 6.372436 & $<0.0001$ & 2.323171 & 4.388694 \\
\hline Brent M1 & 0.820433 & 0.005753 & 142.6219 & $<0.0001$ & 0.809151 & 0.831714 \\
\hline \multicolumn{7}{|l|}{ Regression equation } \\
\hline \multicolumn{7}{|c|}{ min Castilla Dubai@Qiingdao =-4.57309702 + 0.95367646 Brent M1 } \\
\hline $\begin{array}{l}\text { Multiple regression for min } \\
\text { CastillaDubai@Qiingdao }\end{array}$ & \multirow{2}{*}{$\begin{array}{l}\text { Multiple } \\
\quad \text { R }\end{array}$} & \multirow[t]{2}{*}{ R-square } & \multirow{2}{*}{$\begin{array}{c}\text { Adjusted } \\
\text { R- } \\
\text { square } \\
\end{array}$} & \multirow{2}{*}{$\begin{array}{l}\text { Std. err. } \\
\text { of } \\
\text { estimate }\end{array}$} & & \\
\hline \multirow[t]{3}{*}{ Summary } & & & & & & \\
\hline & 0.9915 & 0.9830 & 0.9830 & 3.390663 & & \\
\hline & \multirow{2}{*}{$\begin{array}{l}\text { Degrees of } \\
\text { freedom }\end{array}$} & \multirow{2}{*}{$\begin{array}{l}\text { Sum of } \\
\text { squares }\end{array}$} & \multirow{2}{*}{$\begin{array}{l}\text { Mean of } \\
\text { squares }\end{array}$} & $\mathbf{F}$ & n-value & \\
\hline ANOVA table & & & & & p-value & \\
\hline Explained & 1 & 1435428 & 1435428 & 124856.8 & $<0.0001$ & \\
\hline Unexplained & 2153 & 24752.18 & 11.4966 & & & \\
\hline & Coefficient & $\begin{array}{c}\text { Standard } \\
\text { error }\end{array}$ & t-value & p-value & $\begin{array}{c}\text { Confidence } \\
\text { interval } 95 \%\end{array}$ & \\
\hline Regression table & & & & & Lower & Upper \\
\hline Constant & -4.5731 & 0.247085 & -18.5082 & $<0.0001$ & -5.05765 & -4.08855 \\
\hline Brent M1 & 0.953676 & 0.002699 & 353.3508 & $<0.0001$ & 0.948384 & 0.958969 \\
\hline Regression equation & & & & & & \\
\hline ESPO@Qingdao =0.03872019+1. & 0762764 Brent & M1 & & & & \\
\hline $\begin{array}{l}\text { Multiple Regression for ESPO@ } \\
\text { Qingdao }\end{array}$ & $\underset{\mathbf{P}}{\text { Multiple }}$ & R-square & $\begin{array}{l}\text { Adjusted } \\
\text { R- }\end{array}$ & $\begin{array}{l}\text { Std. err. } \\
\text { of }\end{array}$ & & \\
\hline Summary & & & square & estimate & & \\
\hline & 0.9973 & 0.9946 & 0.9946 & 1.962826 & & \\
\hline & Degrees of & Sum of & Mean of & $\mathbf{F}$ & n-yalue & \\
\hline ANOVA table & freedom & squares & squares & & & \\
\hline Explained & 1 & 1167487 & 1167487 & 303031.9 & $<0.0001$ & \\
\hline Unexplained & 1650 & 6356.932 & 3.852686 & & & \\
\hline & Coefficient & $\begin{array}{c}\text { Standard } \\
\text { error }\end{array}$ & t-value & p-value & $\begin{array}{c}\text { Confidence } \\
\text { interval } 95 \% \\
\end{array}$ & \\
\hline Regression table & & & & & Lower & Upper \\
\hline Constant & 0.03872 & 0.17079 & 0.226712 & 0.8207 & -0.29627 & 0.373708 \\
\hline Brent M1 & 1.007628 & 0.00183 & 550.4833 & $<0.0001$ & 1.004037 & 1.011218 \\
\hline
\end{tabular}

Adding the options value increases this value significantly, to approximately $\$ 118$ million per annum. If the cash flows are not necessarily periodic, the XNPV can be calculated for the project and equals approximately $\$ 1.775$ billion over the 15 years from 2016 to 2030.

(1) $X N P V=\sum_{i=1}^{N} \frac{P_{i}}{\left((1+r)^{\frac{d_{i}-d_{1}}{365}}\right)}$

Where: $d_{i}=$ the i'th payment $d_{1}=$ the o' th payment
$P_{i}=$ the i' $t h$ payment

$d_{i}=$ the i'th payment 
Table-4. Real options value.

\begin{tabular}{|c|c|c|c|c|c|}
\hline \multicolumn{3}{|c|}{ Arab Light vs Minimum Light Composite } & $\begin{array}{l}\text { Arab Medium vs } \\
\text { Minimum Medium } \\
\text { Composite }\end{array}$ & \multicolumn{2}{|c|}{$\begin{array}{c}\text { Arab Heavy vs } \\
\text { Minimum Heavy } \\
\text { Composite }\end{array}$} \\
\hline Asset $1=\mathrm{S} 1(\mathrm{O})$ & $\$$ & 84.94 & $\$ 83.43$ & $\$$ & 81.21 \\
\hline Asset $2=\mathrm{S} 2(\mathrm{O})$ & $\$$ & 87.39 & $\$ 78.10$ & $\$$ & 74.48 \\
\hline Exercise price & $\$$ & 0.820 & 0.82 & \multicolumn{2}{|c|}{0.82} \\
\hline Expiry date & \multicolumn{2}{|c|}{ 12-Aug-2018 } & 12-Aug-2018 & \multicolumn{2}{|c|}{ 12-Aug-2018 } \\
\hline Value (settlement) date & \multicolumn{2}{|c|}{ 12-Jun-2018 } & 12-Jun-2018 & \multicolumn{2}{|c|}{ 12-Jun-2018 } \\
\hline Volatility of asset 1 & \multicolumn{2}{|c|}{$52.27 \%$} & $57.27 \%$ & \multicolumn{2}{|c|}{$60.46 \%$} \\
\hline Volatility of asset 2 & \multicolumn{2}{|c|}{$49.11 \%$} & $58.99 \%$ & \multicolumn{2}{|c|}{$51.16 \%$} \\
\hline Interest rate - annual - Actual/365 & \multicolumn{2}{|c|}{$2.50 \%$} & $2.50 \%$ & \multicolumn{2}{|c|}{$2.50 \%$} \\
\hline Correlation Coefficient & \multicolumn{2}{|c|}{0.998} & 0.995 & \multicolumn{2}{|c|}{0.970} \\
\hline Fair Value of Option & $\$$ & 1.73 & $\$ 0.0008$ & $\$$ & 0.16 \\
\hline Delta of asset 1 & $\$$ & $(0.85)$ & $\$(0.0017)$ & $\$$ & $(0.07)$ \\
\hline Delta of asset 2 & $\$$ & 0.86 & $\$ 0.0018$ & $\$$ & 0.08 \\
\hline Capacity Available & \multicolumn{2}{|c|}{2.98} & 2.98 & \multicolumn{2}{|c|}{2.98} \\
\hline Fair Value of Real Option & $\$$ & 1.7348 & $\$ 0.0008$ & $\$$ & 0.16 \\
\hline Volume of Arab Crude Traded & \multicolumn{2}{|c|}{0.99} & 0.99 & \multicolumn{2}{|c|}{0.99} \\
\hline Fraction of time traded & \multicolumn{2}{|c|}{6.00} & 6.00 & \multicolumn{2}{|c|}{6.00} \\
\hline Option Value $\$$ Millions & $\$$ & 10.34 & 0.00 & \multicolumn{2}{|l|}{$\$$} \\
\hline
\end{tabular}

\section{Results and Conclusion}

Given the assumptions outlined in this case study, the solution to the equation (1), which is the price or fair market value of the option calculated for three separate grades of crude, is:

1. Arabian Light vs. Minimum Light Grade $=\$ 1.14 / \mathrm{bbl}$.

2. Arabian Medium vs. Minimum Medium Grade $=\$ 0.00$.

3. Arabian Heavy vs. Minimum Heavy Grade $=\$ 0.10$.

Note: The zero fair market value for Arabian Medium versus the Minimum Medium Grade arises from the spot prices at the time of estimation using the most recent data for 2016. At mid-year 2016 the spot price for Arabian Medium was $\$ 46.90 / \mathrm{bbl}$, significantly higher than the minimum price of competing crudes, which averaged $\$ 41.83 / \mathrm{bbl}$.

In short, given market conditions at the time of valuation, the most value to be derived from the sale of Arabian Medium crude arises from competition with lighter grades, specifically Arabian Light 34 API versus Russian ESPO 34.8 API plus transportation costs from the Russian far-east port of Kozmino to Qingdao. Given market conditions at the time of estimation, spot sales to this area were highly desirable, and market participants were willing to pay a premium of up to $\$ 1.14 / \mathrm{bbl}$ simply to reserve the right to purchase Arabian Light at market prices FOB JOS for delivery two months from the settlement date.

The capacity to use the JOS storage facility to sell spread options presents considerable potential value to a MOC. That value can be estimated utilizing the spread options model presented in detail in Sections 1-3 of this paper. Given the framework and model construction there is considerable potential for further study and analysis, including:

1 Stochastic Optimization techniques designed to maximize the real options value through the choice of an optimal mix of Heavy, Medium and Light Crude.

2 Stochastic Optimization techniques designed to forecast the sale of spot crudes, and corresponding gravities, to select markets in North America, Latin America, Asia, and Europe.

3 Further sensitivity analysis investigating the effects of changes in transportation costs, production costs, VLCC, freight, rail, and storage charges. 


\begin{tabular}{|c|c|c|c|c|c|c|c|c|c|c|c|c|c|c|c|c|}
\hline & 2016 & 2017 & 2018 & 2019 & 2020 & 2021 & 2022 & 2023 & 2024 & 2025 & 2026 & 2027 & 2028 & 2029 & 2030 & XNPV \\
\hline \multicolumn{17}{|l|}{ Physical quantities million barrels } \\
\hline Storage capacity & 6.20 & 6.20 & 6.20 & 6.20 & 6.20 & 6.20 & 6.20 & 6.20 & 6.20 & 6.20 & 6.20 & 6.20 & 6.20 & 6.20 & 6.20 & \\
\hline Required strategic oil & 3.19 & 3.19 & 3.19 & 3.19 & 3.19 & 3.19 & 3.19 & 3.19 & 3.19 & 3.19 & 3.19 & 3.19 & 3.19 & 3.19 & 3.19 & \\
\hline Slippage & 0.99 & & & & & & & & & & & & & & & \\
\hline \multirow{2}{*}{\multicolumn{17}{|c|}{ Physical quantities million barrels }} \\
\hline & & & & & & & & & & & & & & & & \\
\hline Storage capacity & 6.13 & 6.13 & 6.13 & 6.13 & 6.13 & 6.13 & 6.13 & 6.13 & 6.13 & 6.13 & 6.13 & 6.13 & 6.13 & 6.13 & 6.13 & \\
\hline Required strategic oil & .16 & 3.16 & 3.16 & 3.16 & 3.16 & 3.16 & 3.16 & 3.16 & 3.16 & 3.16 & 3.16 & 3.16 & 3.16 & 3.16 & 3.16 & \\
\hline \multicolumn{17}{|l|}{ Contract revenue } \\
\hline Crude oil futures Dubai ICE & & $\$ 46.9586$ & $\$ 50.2169$ & $\$ 52.4257$ & $\$ 53.5922$ & $\$ 41.3070$ & $\$ 41.3070$ & $\$ 41.3070$ & $\$ 41.3070$ & $\$ 41.3070$ & $\$ 41.3070$ & $\$ 41.3070$ & $\$ 41.3070$ & $\$ 41.3070$ & $\$ 41.3070$ & \\
\hline Arab Light & $\$ 48.21$ & $\$ 46.43$ & $\$ 49.84$ & $\$ 52.14$ & $\$ 53.36$ & $\$ 40.53$ & $\$ 40.53$ & $\$ 40.53$ & $\$ 40.53$ & $\$ 40.53$ & $\$ 40.53$ & $\$ 40.53$ & $\$ 40.53$ & $\$ 40.53$ & $\$ 40.53$ & \\
\hline \multirow{2}{*}{\multicolumn{17}{|c|}{ Assumed $\%$ of Arab Light }} \\
\hline & & & & & & & & & & & & & & & & \\
\hline Arab Medium & 46.90 & $\$ 45.14$ & $\$ 48.53$ & $\$ 50.82$ & $\$ 52.03$ & $\$ 39.27$ & $\$ 39.27$ & $\$ 39.27$ & $\$ 39.27$ & $\$ 39.27$ & $\$ 39.27$ & $\$ 39.27$ & $\$ 39.27$ & $\$ 39.27$ & $\$ 39.27$ & \\
\hline Volume of Arab Medium & & $\$ 0.99$ & $\$ 0.99$ & $\$ 0.99$ & $\$ 0.99$ & $\$ 0.99$ & $\$ 0.99$ & $\$ 0.99$ & $\$ 0.99$ & $\$ 0.99$ & $\$ 0.99$ & $\$ 0.99$ & $\$ 0.99$ & $\$ 0.99$ & $\$ 0.99$ & \\
\hline \multicolumn{17}{|l|}{ Assumed \% of Arab Medium } \\
\hline Arab Heavy & $\$ 45.22$ & $\$ 43.48$ & $\$ 46.82$ & $\$ 49.08$ & $\$ 50.27$ & $\$ 37.69$ & $\$ 37.69$ & $\$ 37.69$ & $\$ 37.69$ & $\$ 37.69$ & $\$ 37.69$ & $\$ 37.69$ & $\$ 37.69$ & $\$ 37.69$ & $\$ 37.69$ & \\
\hline \multirow{2}{*}{\multicolumn{17}{|c|}{ Assumed $\%$ of Arab Heavy }} \\
\hline & & & & & & & & & & & & & & & & \\
\hline \multicolumn{17}{|l|}{ Total revenue } \\
\hline Spot sales revenue AL $\$$ million & $\$ 47.81$ & $\$ 46.05$ & $\$ 49.43$ & $\$ 51.72$ & $\$ 52.92$ & $\$ 40.20$ & $\$ 40.20$ & $\$ 40.20$ & $\$ 40.20$ & $\$ 40.20$ & $\$ 40.20$ & $\$ 40.20$ & $\$ 40.20$ & $\$ 40.20$ & $\$ 40.20$ & \\
\hline Spot sales revenue AM $\$$ million & $\$ 46.52$ & $\$ 44.77$ & $\$ 48.13$ & $\$ 50.40$ & $\$ 51.60$ & $\$ 38.95$ & $\$ 38.95$ & $\$ 38.95$ & $\$ 38.95$ & $\$ 38.95$ & $\$ 38.95$ & $\$ 38.95$ & $\$ 38.95$ & $\$ 38.95$ & $\$ 38.95$ & \\
\hline Spot sales revenue AL $\$$ million & $\$ 44.85$ & $\$ 43.12$ & $\$ 46.43$ & $\$ 48.67$ & $\$ 49.86$ & $\$ 37.39$ & $\$ 37.39$ & $\$ 37.39$ & $\$ 37.39$ & $\$ 37.39$ & $\$ 37.39$ & $\$ 37.39$ & $\$ 37.39$ & $\$ 37.39$ & $\$ 37.39$ & \\
\hline $\begin{array}{l}\text { Total revenue } \\
\end{array}$ & $\$ 139.18$ & $\$ 133.95$ & $\$ 143.99$ & $\$ 150.79$ & $\$ 154.39$ & $\$ 116.53$ & $\$ 116.53$ & $\$ 116.53$ & $\$ 116.53$ & $\$ 116.53$ & $\$ 116.53$ & $\$ 116.53$ & $\$ 116.53$ & $\$ 116.53$ & $\$ 116.53$ & $\$ 1,886.74$ \\
\hline \multirow{2}{*}{\multicolumn{17}{|c|}{$\frac{\text { Inflation }}{\text { Costs of crude oil supplies }}$}} \\
\hline & & & & & & & & & & & & & & & & \\
\hline \multicolumn{17}{|l|}{ Crude oil supplies } \\
\hline \multicolumn{17}{|l|}{$\begin{array}{ll}\text { Production costs per barrel } & \$ 3.25 \\
\end{array}$} \\
\hline \multicolumn{2}{|l|}{$\begin{array}{lll}\text { Production costs } & 9.67 \\
\text { Transportation cost from MPT to JOS } & \text { (At }\end{array}$} & 9.91 & 10.16 & 10.41 & 10.67 & 10.94 & 11.21 & 11.49 & 11.78 & 12.08 & 12.38 & 12.69 & 13.01 & 13.33 & 13.66 & \\
\hline $\begin{array}{l}\text { Transportation cost from MPT to JOS } \\
1.67 / \mathrm{Bbl})\end{array}$ & $\begin{array}{lll}(\text { At } \\
4.97\end{array}$ & $\$ 5.09$ & $\$ \quad 5.22$ & $\$ 5.35$ & $\$ 5.48$ & $\$ 5.62$ & $\$ 5.76$ & $\$ 5.91$ & $\$ 6.05$ & $\$ 6.21$ & $\$ 6.36$ & $\$ 6.52$ & $\$ 6.68$ & $\$ 6.85$ & $\$ 7.02$ & \\
\hline \multicolumn{17}{|l|}{ Operating expenses } \\
\hline Operating & $2 \% \$ 0.52$ & $\$ \quad 0.53$ & $\$ \quad 0.55$ & $\$ \quad 0.56$ & $\$ \quad 0.57$ & $\$ \quad 0.59$ & $\$ \quad 0.60$ & $\$ \quad 0.62$ & $\$ \quad 0.63$ & $\$ \quad 0.65$ & $\$ \quad 0.67$ & $\$ \quad 0.68$ & $\$ \quad 0.70$ & $\$ \quad 0.72$ & $\$ \quad 0.73$ & \\
\hline Other & $\$ 0.50$ & $\$$ & \begin{tabular}{|c|c|}
$\$$ & 0.53 \\
\end{tabular} & $\$ \quad 0.54$ & $\$ \quad 0.55$ & $\$ 0.57$ & $\$ \quad 0.58$ & $\$ \quad 0.59$ & $\$ \quad 0.61$ & $\$ \quad 0.62$ & $\$ \quad 0.64$ & $\$ \quad 0.66$ & \begin{tabular}{|l|l|}
$\$$ & 0.67 \\
\end{tabular} & \begin{tabular}{|l|l|} 
& 0.69 \\
\end{tabular} & 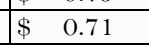 & \\
\hline Facilities & $\$-$ & $\$-$ & $\$-$ & $\$-$ & $\$-$ & $\$-$ & $\$-$ & $\$-$ & $\$-$ & $\$-$ & $\$-$ & $\$-$ & $\$-$ & $\$-$ & $\$-$ & \\
\hline Total operating expenses & 15.66 & $\$ 16.05$ & $\$ 16.45$ & $\$ 16.86$ & $\$ 17.28$ & $\$ 17.72$ & $\$ 18.16$ & $\$ 18.61$ & $\$ 19.08$ & $\$ 19.56$ & $\$ 20.04$ & $\$ 20.55$ & $\$ 21.06$ & $\$ 21.59$ & $\$ 22.13$ & \\
\hline $\begin{array}{l}\text { Gross income without option value: } \\
\text { EBITDA }\end{array}$ & $\$ 123.52$ & $\$ 117.90$ & $\$ 127.53$ & $\$ 133.93$ & $\$ 137.10$ & $\$ 98.81$ & $\$ 98.37$ & $\$ 97.92$ & $\$ 97.45$ & $\$ 96.97$ & $\$ 96.49$ & $\$ 95.98$ & $\$ 95.47$ & $\$ 94.94$ & $\$ 94.40$ & $\$ 1,606.09$ \\
\hline & $\$ 123.52$ & $\$ 241.41$ & $\$ 368.95$ & $\$ 502.88$ & $\$ 639.98$ & $\$ 738.79$ & $\$ 837.17$ & $\$ 935.08$ & $\$ 1,032.53$ & $\$ 1,129.51$ & $\$ 1,225.99$ & $\$ 1,321.98$ & $\$ 1,417.45$ & $\$ 1,512.39$ & $\$ 1,606.80$ & \\
\hline \multicolumn{17}{|c|}{ 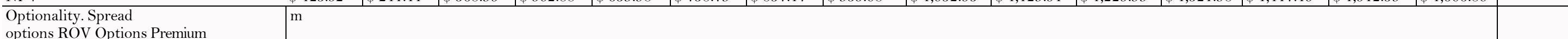 } \\
\hline $\begin{array}{l}\text { Revenue from spot sales of Arab Light } \\
\$ / \mathrm{bbl}\end{array}$ & \begin{tabular}{l|l|l} 
& $\$ 10.34$ \\
\end{tabular} & $\$ 10.34$ & $\$ 10.34$ & $\$ 10.34$ & $\$ 10.34$ & $\$ 10.34$ & $\$ 10.34$ & $\$ 10.34$ & $\$ 10.34$ & $\$ 10.34$ & $\$ 10.34$ & $\$ 10.34$ & $\$ 10.34$ & $\$ 10.34$ & $\$ 10.34$ & \\
\hline $\begin{array}{l}\text { Revenue from spot sales } \\
\text { of Arab Medium } \$ / \mathrm{bbl}\end{array}$ & $\$ 0.00$ & $\$ \quad 0.00$ & $\$ \quad 0.00$ & $\$ \quad 0.00$ & $\$ \quad 0.00$ & $\$ \quad 0.00$ & $\$ \quad 0.00$ & $\$ \$ \quad 0.00$ & $\$ \quad 0.00$ & $\$ 0.00$ & $\$ \quad 0.00$ & $\$ \quad 0.00$ & \begin{tabular}{|l|l|}
$\$$ & 0.00
\end{tabular} & $\$ \$ \quad 0.00$ & $\$ \quad 0.00$ & \\
\hline \multicolumn{2}{|l|}{$\begin{array}{l}\text { Revenue from spot sales of Arab Heavy } \$ / b b l \\
\$ 0.95\end{array}$} & $\$ 0.95$ & $\$ \quad 0.95$ & $\$ \quad 0.95$ & $\$ \quad 0.95$ & $\$ \quad 0.95$ & $\$ \quad 0.95$ & 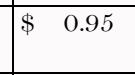 & $\$ 0.95$ & $\$ 0.95$ & $\$ 0.95$ & $\$ 0.95$ & $\$ \quad 0.95$ & $\$ \quad 0.95$ & $\$ \quad 0.95$ & \\
\hline $\begin{array}{ll}\text { Percent of storage capacity } \quad 50 \% \\
\end{array}$ & $\$ \$ 3.07$ & $\$ \quad 3.07$ & $\$ 3.07$ & $\$ 3.07$ & $\$ \quad 3.07$ & $\$ \quad 3.07$ & $\$ \quad 3.07$ & $\$ \quad 3.07$ & $\begin{array}{|ll|}\$ & 3.07\end{array}$ & $\$ 3.07$ & $\$ \quad 3.07$ & \begin{tabular}{|ll}
$\$$ & 3.07
\end{tabular} & $\$ \quad 3.07$ & \begin{tabular}{|ll} 
& 3.07
\end{tabular} & \begin{tabular}{|ll} 
& 3.07
\end{tabular} & \\
\hline
\end{tabular}


Asian Bulletin of Energy Economics and Technology, 2021, 6(1): 30-42

\begin{tabular}{|c|c|c|c|c|c|c|c|c|c|c|c|c|c|c|c|c|}
\hline $\begin{array}{l}\text { Total revenue from strategic options } \$ \\
\text { million }\end{array}$ & $\$ 11.30$ & $\$ 11.30$ & $\$ 11.30$ & $\$ 11.30$ & $\$ 11.30$ & $\$ 11.30$ & $\$ 11.30$ & $\$ 11.30$ & $\$ 11.30$ & $\$ 11.30$ & $\$ 11.30$ & $\$ 11.30$ & $\$ 11.30$ & $\$ 11.30$ & $\$ 11.30$ & $\$ 169.40$ \\
\hline Incremental value of strategic option & 11.30 & $\$ 11.30$ & 1.30 & 1.30 & 11.30 & 11.30 & 11.30 & 1.30 & 1.30 & 30 & 1.30 & 1.30 & 1.30 & 11.30 & 11.30 & \\
\hline t oil sales from JOS & $\$ 123.52$ & $\$$ & 53 & 93 & $\$ 1$ & $\$ 98$ & $\$ 98.37$ & $\$ 97.92$ & $\$ 97.45$ & 97 & $\$ 96.49$ & 98 & $\$ 95.47$ & $\$ 94.94$ & $\$ 94.40$ & \\
\hline Gross in & $\$ 134.8$ & - & 38.83 & $\$$ & 148. & $\$ 1$ & $\$ 109.67$ & $\$ 10$ & $\$ 108.75$ & $\$ 1$ & $\$ 107.78$ & $\$ 1$ & $\$ 1$ & 24 & $\$ 105.70$ & \\
\hline Gross income: EBITDA & $\$ 134.82$ & $\$ 12$ & 138.83 & 3 & 148. & $\$ 11$ & $\$ 109.67$ & $\$ 109.22$ & $\$ 108.75$ & $\$ 108.27$ & $\$ 107.78$ & $\$ 107.28$ & $\$ 106.77$ & $\$ 106.24$ & $\$ 105.70$ & $\$ 1,775.49$ \\
\hline$\overline{\mathrm{NPV}}$ & $\$ 134.82$ & $\$ 264.01$ & $\$ 402.84$ & $\$ 548.07$ & $\$ 696.47$ & $\$ 806.59$ & $\$ 916.26$ & $\$ 1,025.47$ & $\$ 1,134.22$ & $\$ 1,242.49$ & $\$ 1,350.28$ & $\$ 1,457.56$ & $\$ 1,564.33$ & $\$ 1,670.57$ & $\$ 1,776.28$ & \\
\hline
\end{tabular}




\section{Abbreviations:}

- FOB - free on board

- IEA - International Energy Agency

- JOS - joint oil stockpiling

- METI - Ministry of Economy, Trade, and Industry

- $\mathrm{MPT}$ - main point of transit

- MOC - major oil company

- $\mathrm{SPR}$ - strategic petroleum reserves

- ULCC - ultra large crude carriers

- VLCC - very large crude carriers

\section{References}

Al-Kathiri, N., Yazeed, A.-R., Tilak, K. D., \& Frederic, H. M. (2017). Asian Premium' of 'North Atlantic Discount: Does geographical diversification in oil trade always impose costs? Energy Economics, 66, 411-420.Available at: https://doi.org/10.1016/j.eneco.2017.07.005.

Black, F., \& Scholes, M. (1973). The pricing of options and corporate liabilities. The Journal of Political Economy, 81(3), 637-654.

Bloomberg Staff. (2015). China surpasses Canada as top buyer of U.S. Crude. Bloomberg.Com, April 4, 2017. Retrieved from: https://www.bloomberg.com/news/articles/2017-04-04/china-surpasses-canada-as-top-u-s-crude-buyer-amid-record-sales. New York, NY, Bloomberg.

Borovkova, S., Permana, F., \& Van Der Weide, J. (2012). American basket and spread option pricing by a simple binomial tree. The Journal of Derivatives, 19(4), 29-38.Available at: https://doi.org/10.3905/jod.2012.19.4.029.

Carmona, R., \& Durrleman, V. (2003). Pricing and hedging spread options. Siam Reviewe, 45(4), 627-685.Available at: https://doi.org/10.1137/Soo36144503424798.

CME Group. (2016). Brent crude oil futures quotes - CME Group. Retrieved from: https://www.cmegroup.com/trading/energy/crudeoil/brent-crude-oil.html, New York, NYl, CME Group.

Doshi, T. K., \& Sammy, S. (2017). Joint oil stockpiling between middle east exporters and Northeast Asian Importers: A winning formula. KAPSARC.

Garman, M. (1992). Spread the load. Risk, 5(11), 68-84.

JNOC. (2001). Outline of petroleum stockpiling in Japan: Japan's emergency preparedness measure. Bancock: APEC.

Kilduff, J. (2015). Oil prices have moved into 'Super Contango'-—commentary. New York: CNBC.

Merton, R. C. (1973). Theory of rational option pricing. The Bell Journal of Economics and Management Science, 4(1), 141-183.Available at: https://doi.org/10.2307/3003143.

Natarajan, K. (2007). Pricing a class of multiasset options using information on smaller subsets of assets. Retrieved from: http://www.optimization-online.org.

Phua, P., \& Jean, W. (2016). Chinese teapots - the game changer in China's oil industry. UK: Ashurst News and Insights.

Platts. (2016). Market data - Oil |SEP global platts. Boston, Massachusetts, Platts: McGraw Hill Financial.

Platts. (2018). Market data - Oil $\mid S \& P$ global platts. Boston, Massachusetts, Platts: McGraw Hill Financial.

Rasheed, A. (2018). Iraq May build oil storage in Japan, South Korea to Drive Asian Sales. Reuters, March 27, 2018. Retrieved from: https://www.reuters.com/article/us-iraq-oil-japan-southkorea-idUSKBN1H31EK, Beijing, China, Reuters.

Reuters. (2016). Japan, Saudi Aramco extend Okinawa crude storage deal. India: Reuters Energy.

Reuters, S. (2017). Japan, Saudi Aramco extend Okinawa crude storage deal. Reuters, December 10, 2019. Retrieved from: https://www.reuters.com/article/us-japan-saudi-aramco-crude-idUSKBN1YE178, Tokyo, Japan, Reuters.

Rubinstein, M. (1994). Return to Oz. Risk 7, London, UK, Risk.

Traywick, C., \& Sheela, T. (2017). China surpasses canada as top buyer of U.S. Crude.

Valdo Durrleman, R. C. (2003). Pricing and Hedging Spread Options. Society for Industrial and Applied Mathematics, 627-685.

Verma, N. (2017). India to fill mangalore strategic reserve with UAE Oil. Retrieved from: http://in.reuters.com/article/india-emiratesidINKBN 1590RM.

\section{Appendix: The Mathematical Model: A “Spread Option”}

For the sake of simplicity, the analysis was restricted to the case of a simple European Style spread option between two underlying assets. American options are considerably more difficult to value than European style options because they can be exercised at any time before the expiry date. The analysis can be extended to the American Style spread options between more than one asset, or even a basket or portfolio of assets (Borovkova, Permana, \& Van Der Weide, 2012). Alternatively, Natarajan (2007) examines the pricing process for a class of multi-asset European options based on a piecewise linear convex payoff in asset prices. Both of these methodologies have the capacity to add value to the analysis and are recommended as an area of future research.

Given the compound price index $S_{1}=\left\{S_{1}(t)\right\}_{t \geq 0}$ and, underlying asset price $S_{2}=\left\{S_{2}(t)\right\}_{t \geq 0}$, the spread will be the difference between the two instruments.

$$
S(t)=S_{2}(t)-S_{1}(t), t \geq 0
$$

Where:

$\mathrm{S}_{1}(\mathrm{t})=$ The compound price index computed from the aggregation of a number of crude oil prices reflecting the minimum price at time $t$ of all competing crudes FOB China Qingdao port.

$\mathrm{S}_{2}(\mathrm{t})=$ The price of Arabian Medium FOB JOS at time $\mathrm{t}$.

A player is said to be buying the spread, if he purchases $S_{2}$ and sells $S_{1}$. He will make a profit on the transaction if the minimum price that he receives from selling crude FOB Qingdao port minus the costs of purchasing the crude - Arabian Medium FOB JOS - is greater than the exercise price, which is defined as the cost of transportation from JOS to Qingdao.

The purpose of this section is to calculate the "price" of a simple European call option on the spread between $\mathrm{S}_{1}$ and $\mathrm{S}_{2}$. That is the fair market value of the right to purchase the spread, at a fixed exercise, or strike price, which has been set equal to the cost of transportation from JOS to Qingdao. As mentioned above, European call options differ from their American cousins as they can only be exercised at expiry date T. They are defined by the date of expiry, the strike or exercise price and the value of the underlying instruments. (The American option can be exercised at any date prior to expiry, and as a result is considerably more difficult to calculate.) 
The payoff of the spread option is given as:

$$
(S(T)-K)^{+}=(S(T)-K) 1_{\{S(T)>K\}}
$$

Where:

$\mathrm{S}(\mathrm{T})$ is defined in Equation \#1

$\mathrm{T}=$ The expiry date of the option.

$K=$ The strike or exercise price of the option. In this case the exercise price is equal to the cost of transportation from JOS to Qingdao

Following Black and Scholes (1973) and Merton (1973) the price of the European call option $p(t, x)$ at time $t$, when $\mathrm{S}(\mathrm{t})=\mathrm{x}$ is given by the solution to the backward parabolic PDE:

$$
\begin{aligned}
& \partial_{t} p(t, x)+\frac{1}{2} \sigma^{2} x^{2} \partial_{x x}^{2} p(t, x)+r x \partial_{x} p(t, x)-r p(t, x)=0 \\
& \text { and terminal condition: } p(T, x)=(x-K)^{+}
\end{aligned}
$$

Where:

$$
\begin{aligned}
& r=\text { the short-term risk free interest rate. } \\
& \sigma=\text { The volatility of the underlying asset }
\end{aligned}
$$

When $\mathrm{S}(\mathrm{T})$ has a log-normal distribution:

$$
\text { 4. } \quad p=E\left\{e^{-r t}(S(T)-K)^{+}\right\}
$$

This can be solved explicitly for $\mathrm{p}$ given values for $\mathrm{S}(\mathrm{O})$, $\mathrm{T}, \mathrm{r}$ and $\mathrm{K}$

$$
5 \quad p=S(0) \emptyset\left(d_{1}\right)-K e^{-r t} \emptyset\left(d_{2}\right)
$$

Where

$$
d_{1}=\frac{\ln \left(\frac{s(0) e^{-r t}}{K}\right)}{\sigma \sqrt{T}}+\frac{1}{2} \sigma \sqrt{T} \quad \text { and } \quad d_{2}=d_{1}-\sigma \sqrt{T}
$$

$\emptyset(x)$ is the cumulative distribution function for the standard normal distribution with mean zero, and standard deviation of $1, N(0,1)$

The spread option is the difference between a European call option on asset 1 and a European put option on asset 2, with identical maturity T, and strike price K. It is given by the risk neutral expectation: (Valdo Durrleman, 2003)

6

$$
p=e^{-r t} E\left\{\left(S_{2}(T)-S_{1}(T)-K\right)^{+}\right\}
$$

At expiry T:

$$
p=e^{-r T} \iint\left(s_{2}-s_{1}-K\right)^{+} f_{T}\left(s_{1} s_{2}\right) d_{s_{1}} d_{s_{2}}
$$

The solution to the double integral described in equation 6 is obtained numerically, using Monte Carlo Simulation (Rubinstein, 1994), (Garman, 1992). 